\title{
PEBRA trial - effect of a peer-educator coordinated preference-based ART service delivery model on viral suppression among adolescents and young adults living with HIV: protocol of a cluster-randomized clinical trial in rural Lesotho
}

Thabo Ishmael Lejone ${ }^{1}$, Mathebe Kopo ${ }^{1}$, Nadine Bachmann 2,3, Jennifer Anne Brown ${ }^{2,3,4}$, Tracy Renée Glass²,3, Josephine Muhairwe ${ }^{1}$, Tebatso Matsela ${ }^{5}$, Ramona Scherrer ${ }^{2,3}$, Lebohang Chere ${ }^{6}$, Tilo Namane ${ }^{7}$, Niklaus Daniel Labhardt ${ }^{2,3,8}$ and Alain Amstutz ${ }^{2,3,8^{*}}$

\footnotetext{
Abstract

Background: Despite tremendous progress in controlling the HIV epidemic in sub-Saharan Africa, HIV-related mortality continues to increase among adolescents and young people living with HIV (AYPLHIV). Globally, subSaharan Africa accounts for $85 \%$ of the AYPLHIV. Overall outcomes along the HIV care cascade are worse among AYPLHIV as compared to all other age groups due to various challenges in accessing and adhering to antiretroviral therapy (ART). New, innovative multicomponent packages of differentiated service delivery (DSD) models, are required to address the specific needs of AYPLHIV. This study aims to evaluate the feasibility and effectiveness of a multicomponent DSD model (PEBRA model) designed for AYPLHIV and coordinated by a peer-educator.

(Continued on next page)
}

\footnotetext{
* Correspondence: alain.amstutz@swisstph.ch

${ }^{2}$ Department of Medicine, Clinical Research Unit, Swiss Tropical and Public

Health Institute, Socinstrasse 57, 4051 Basel, Switzerland

${ }^{3}$ University of Basel, Basel, Switzerland

Full list of author information is available at the end of the article
}

C C The Author(s). 2020 Open Access This article is licensed under a Creative Commons Attribution 4.0 International License, which permits use, sharing, adaptation, distribution and reproduction in any medium or format, as long as you give appropriate credit to the original author(s) and the source, provide a link to the Creative Commons licence, and indicate if changes were made. The images or other third party material in this article are included in the article's Creative Commons licence, unless indicated otherwise in a credit line to the material. If material is not included in the article's Creative Commons licence and your intended use is not permitted by statutory regulation or exceeds the permitted use, you will need to obtain permission directly from the copyright holder. To view a copy of this licence, visit http://creativecommons.org/licenses/by/4.0/ The Creative Commons Public Domain Dedication waiver (http://creativecommons.org/publicdomain/zero/1.0/) applies to the data made available in this article, unless otherwise stated in a credit line to the data. 


\begin{abstract}
(Continued from previous page)
Methods: PEBRA (Peer-Educator Based Refill of ART) is a cluster randomized, open-label, superiority trial conducted at 20 health facilities in three districts of Lesotho, Southern Africa. The clusters (health facilities) are randomly assigned to either the PEBRA model or standard of care in a 1:1 ratio, stratified by district. AYPLHIV aged 15-24 years old in care and on ART at one of the clusters are eligible. In the PEBRA model, a peer-educator coordinates the antiretroviral therapy (ART) services - such as medication pick-up, SMS notifications and support options according to the preferences of the AYPLHIV. The peer-educator delivers this personalized model using a tabletbased application called PEBRApp. The control clusters continue to offer standard of care: ART services coordinated by the nurse. The primary endpoint is viral suppression at 12 months. Secondary endpoints include self-reported adherence to ART, quality of life, satisfaction with care and engagement in care. The target sample size is 300 AYPLHIV. Statistical analyses are conducted and reported in line with CONSORT guidelines for cluster randomized trials.

Discussion: The PEBRA trial will provide evidence on the feasibility and effectiveness of an inclusive, holistic and preference-based DSD model for AYPLHIV that is coordinated by a peer-educator. Many countries in SSA have an existing peer-educator program. If proven effective, the PEBRA model and PEBRApp have the potential to be scaled up to similar settings.
\end{abstract}

Trial registration: Clinicaltrials.gov, NCT03969030. Registered on 31 May 2019. More information: www.pebra.info

Keywords: HIV, Adolescent, Lesotho, Africa, southern, Randomized controlled trial, Peer group, Antiretroviral therapy, differentiated service delivery

\section{Background}

There is encouraging progress towards an AIDS-free generation by 2030 on a global scale. However, this progress is challenged by persistent poor outcomes among young people in sub-Saharan Africa (SSA). SSA accounts for $85 \%$ of the adolescents and young people living with HIV (AYPLHIV) worldwide. Almost one third of new HIV infections occur among individuals aged 15-25 years, mostly in females $[1,2]$. AYPLHIV is the only population group for whom HIV-related mortality continues to increase and they are more likely to drop out of HIV care, and have overall worse health outcomes than all other age groups, especially in rural areas [3-7]. AYPLHIV face particular challenges in accessing and adhering to ART. The distinct rapid physical, psychological and emotional changes that occur during adolescence impact on how AYPLHIV perceive their health, make decisions, handle risks and interact with health and related services [8]. Thus, barriers in the adolescent HIV care cascade are multifactorial [9-13]. Multicomponent packages of differentiated service delivery (DSD) are a promising approach to address these multiple barriers $[14,15]$. Unlike service delivery models that apply standardized care for all people living with HIV, the idea of DSD models is to consider the specific needs of a group of people, while facilitating service scale-up by reducing the burden on health systems and increasing efficiency [16, 17]. In 2018, Paediatric-Adolescent Treatment Africa, in collaboration with other key stakeholders, undertook a situational analysis of DSD for AYPLHIV in South Africa [18]. They report a lack of published literature documenting adolescent-specific DSD models in the Southern African region. Moreover, the analysis shows that most adolescents are not accessing DSD models even where they exist, an indicator that the existing DSD models are not tailored according to adolescent-specific preferences.

Many countries in SSA are expanding their peereducator (PE) program and the World Health Organization (WHO) and International AIDS Society highly recommend engagement of peers in service delivery $[19,20]$. The question arises to which extent PEs can be involved in coordinating DSD models and ART services for their peers. Some evidence exists, including a systematic review showing that PE involvement leads to improved engagement in care, psychosocial well-being and HIV knowledge, however, PE involvement is usually limited to support group interventions in urban settings with an unclear effect on biological outcomes [21-23]. One recent cluster-randomized clinical trial from rural Zimbabwe demonstrated a positive impact of peer-led services on psychosocial as well as virological outcomes for AYPLHIV [24, 25].

Lesotho has the second-highest HIV prevalence in the world with and adult prevalence of $25.6 \%$ and one of the highest HIV incidences among adolescent girls and young women $[1,26]$. According to the recent household-based national survey (LePHIA) overall viral suppression in AYPLHIV is $50.9 \%$ among female and $46.1 \%$ among male [27]. In close collaboration with different local stakeholders, we designed a DSD model specifically for AYPLHIV, called the PEBRA model, built upon existing support structures in Lesotho and delivered by a dedicated tablet application. In the PEBRA model, PEs first assess the ART 
service preferences of their peers, and then differentiate the services according to these preferences in a feasible manner.

\section{Methods/design \\ Setting}

The PEBRA trial will be conducted in northern Lesotho, in the districts of Leribe, Butha-Buthe and Mokhotlong. All districts are characterized by mostly rural settings, poor transport infrastructure and hard-to-reach villages with a combined estimated population of ca. 550'000. Butha-Buthe district comprises 12 public/missionary health facilities, Leribe district 26, and Mokhotlong district 10 that offer ART services. The HIV prevalence among individuals $15-59$ years old ranges from $17.8 \%$ in Butha-Buthe, to $23.7 \%$ in Leribe and $26.1 \%$ in Mokhotlong [27].

\section{Design}

PEBRA trial is a cluster randomized, open-label, superiority trial in rural Lesotho. The clusters (health facilities) are randomized into two groups (intervention and control) in a 1:1 allocation stratified by district. Cluster randomization was applied to eliminate the risk of crosscontamination between the study arms.

\section{Eligibility and randomization}

Eligible clusters are public or missionary nurse-led health facilities (not hospitals) that offer ART services, serve a rural population, are situated in an area with stable cell phone signal and have a PE who passes the study-specific training assessment. Randomization is stratified by district due to differences in viral suppression rates across the districts. To obtain consent and to maximize transparency and ownership of the health facilities, randomization events involving all health facilities and the District Health Management Team were conducted in each district. At these events, health facility representatives drew opaque, sealed, equally sized envelopes containing the group allocation from a Mokorotlo (traditional Lesotho hat) and disclosure took place only once all facilities had drawn their envelope. To further ensure allocation concealment and to minimize potential selection bias, the sequence of drawing was randomly selected in advance by an independent person drawing from a second pile of opaque, sealed envelopes containing the names of the facility.

The PEs actively screen all young people at their facility for inclusion. Eligible individuals are attending care at a participating facility, take ART, 15-24 years old, and provide written informed consent.

\section{Control clusters}

Participants in the control clusters receive the standard of care offered in Lesotho at nurse-led rural health facilities. The ART visits and refills are clinic-based and coordinated by the nurse. Some of the clinics have functioning clinic or community support clubs as well as SMS notifications to inform when VL results are available.

\section{Intervention clusters}

The participants in the intervention clusters are offered the PEBRA model. In the PEBRA model, the ART services are coordinated by the $\mathrm{PE}$ as much as feasible and depending on the participants' preferences regarding medication pick-up, SMS notifications and support options. Details are outlined in Fig. 1. First, the PE explains all options to the participant who then chooses according to his/her preferences. Thereafter, the PE systematically assesses the feasibility of the option chosen as not all options are available to everyone all the time, e.g. no nearby Village Health Worker (VHW) available who could dispense ART, or no community youth club established in the participants' community, or homedelivery by the PE not being feasible. Finally, the compromise between preference and feasibility is delivered. The preferences are assessed at enrolment and thereafter follow a strict schedule: every month for participants with unsuppressed VL (> 1000 copies $/ \mathrm{mL}$ ) and every 3 months for participants with suppressed VL. The PE delivers the PEBRA model using a tablet-based application, called PEBRApp (Fig. 2). The PEBRApp helps the PE to assess the preferences, to deliver them in a feasible manner, to keep track of the ART refill and next assessment dates, and to ensure regular contact between the $\mathrm{PE}$ and the participant. The PEBRApp is protected by a password and does not entail confidential patient information, i.e. names. The chosen SMS notifications are sent automatically through an external platform, and always include a call-back option to the PE's number.

The PEBRA model and PEBRApp were designed in collaboration with peer-educators, AYPLHIV, youth advocates, clinical staff and application developers during several workshops supported and coordinated by two local non-profit organizations (SolidarMed \& Sentebale) as well as the Ministry of Health of Lesotho. The model incorporates the existing support structures at the health facilities. Sentebale is running a longstanding PE program in collaboration with the Ministry of Health. The study PEs are recruited from this existing PE program. They are trained young people living in a community of their respective health facility catchment area. All PEs involved in PEBRA trial receive an additional training on the PEBRApp and use of the tablet, referral and documentation system, obtaining 


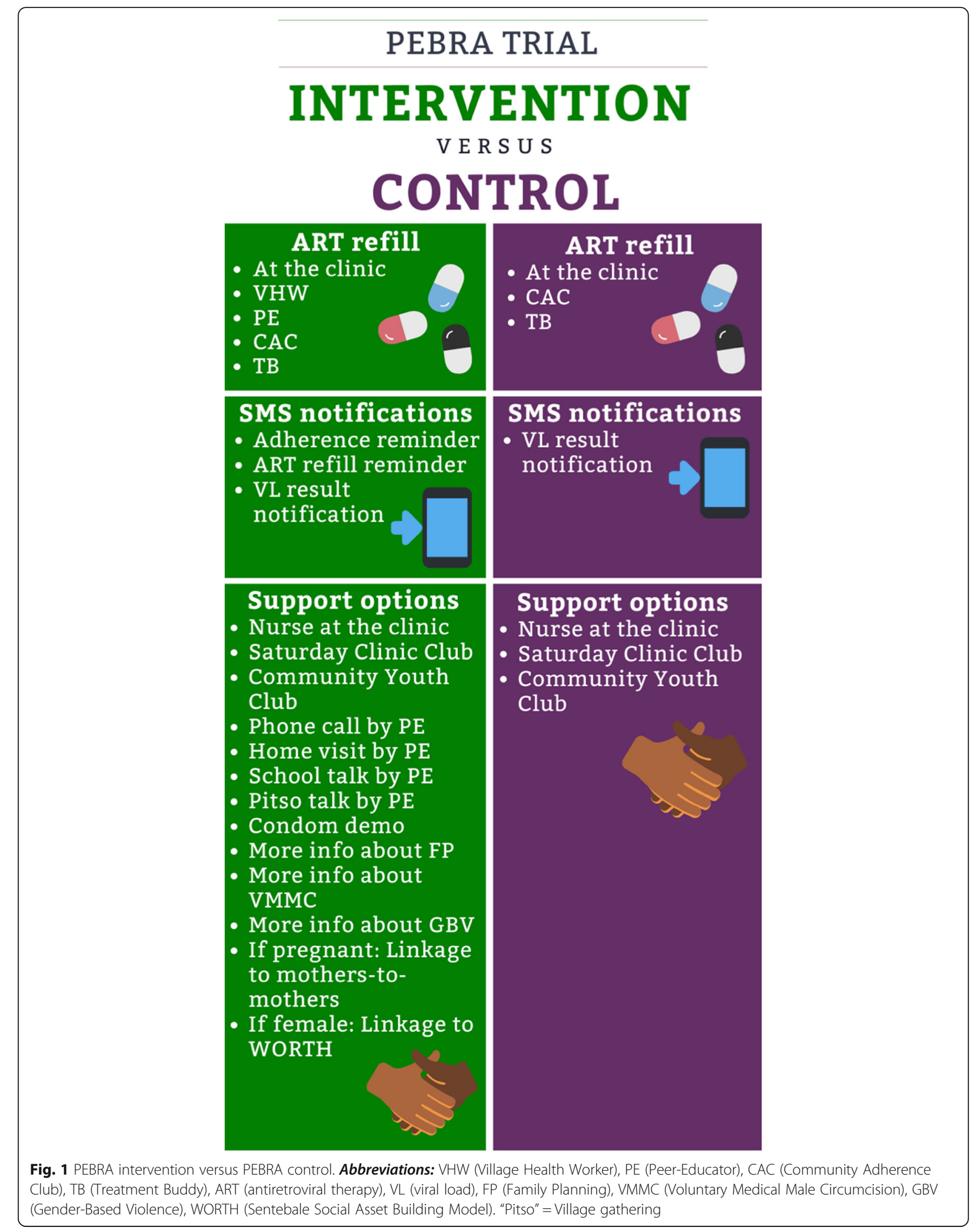



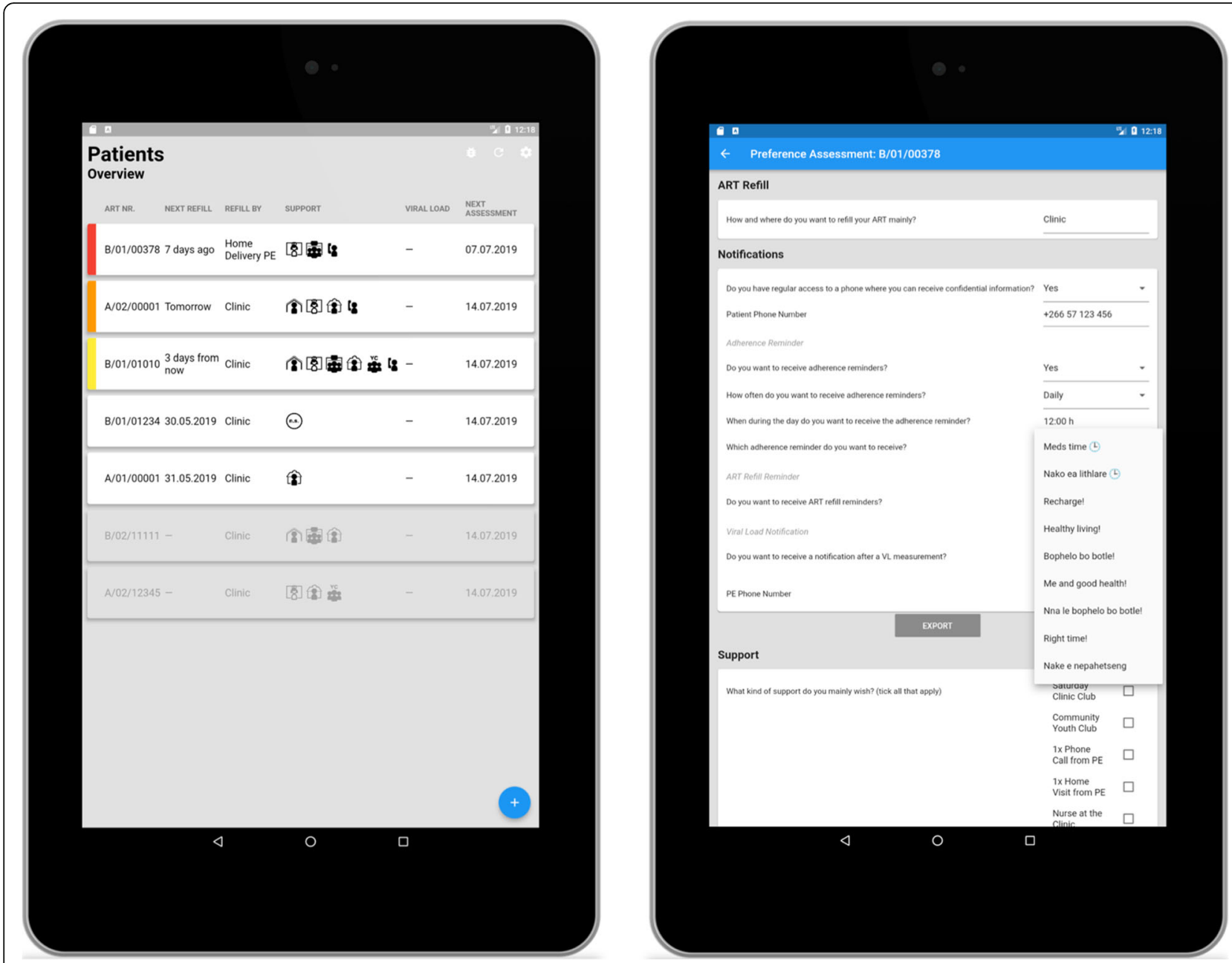

Fig. 2 PEBRApp

informed consent and other study-specific procedures. Besides their usual close supervision by the health facility staff and Sentebale they are supervised by the study staff with regular onsite monitoring visits.

\section{Outcomes}

The primary endpoint is viral suppression at 12 months, defined as the proportion of participants in care with a documented $\mathrm{VL}<20$ copies/mL 12 months (range: 9-15 months) after enrolment out of all participants enrolled, including participants who transferred out to any other health facility with documented proof of a VL laboratory report in the endpoint window. The secondary endpoints are defined in Table 1. Furthermore, qualitative research to explore the acceptability of the PEBRA model and a cost-effectiveness analysis to estimate the impact of PEBRA model on health outcomes and costs will be conducted.

\section{Data collection and management}

At enrolment, the PE administers a questionnaire integrated in the PEBRApp. Questionnaire domains include sociodemographic and socioeconomic data, medical history, HIV/AIDS knowledge, adherence, quality of life and satisfaction of care. Follow-up data is collected using PEBRApp according to the schedule outlined in Fig. 3. Baseline VL is defined as the last VL within the previous 12 months. If no VL within previous 12 months available, then the participant is sent to the nurse for routine VL measurement at enrolment.

The PEBRApp is password-protected and all data is regularly backed up into at a password-protected database. Similarly, relevant data for the SMS intervention is uploaded to a separate encrypted and passwordprotected online database that offers the possibility to send out SMS automatically and is connected to the district laboratory database containing the VL results. SMS are dispatched using the trusted third-party provider 
Table 1 Secondary endpoints of PEBRA trial

\begin{tabular}{|c|c|c|c|}
\hline $\begin{array}{l}\text { Secondary } \\
\text { endpoints } \\
\end{array}$ & Definition & $\begin{array}{l}\text { Time point following } \\
\text { enrolment }\end{array}$ & Remarks \\
\hline $\begin{array}{l}\text { Engagement } \\
\text { in care }\end{array}$ & Proportion of all participants engaged in care & $\begin{array}{l}6 \text { months (range 5-8) and } \\
12 \text { months (range 9-15) }\end{array}$ & $\begin{array}{l}\text { Definition of "in care": at least one ART visit in the } \\
\text { defined window } \\
\text { I. Including participants who transferred out to any } \\
\text { other health facility with known outcome } \\
\text { (documented proof of follow-up visit or laboratory } \\
\text { test) }\end{array}$ \\
\hline $\begin{array}{l}\text { All cause } \\
\text { mortality }\end{array}$ & Proportion of all participants who died & $\begin{array}{l}6 \text { months (range } 5-8 \text { ) and } \\
12 \text { months (range } 9-15 \text { ) }\end{array}$ & $\begin{array}{l}\text { Verbal autopsy to capture cause of death whenever } \\
\text { possible. No death certificate or autopsy report } \\
\text { required. }\end{array}$ \\
\hline $\begin{array}{l}\text { Lost-to- } \\
\text { follow-up } \\
\text { (LTFU) }\end{array}$ & Proportion of all participants LTFU & $\begin{array}{l}6 \text { months (range } 5-8 \text { ) and } \\
12 \text { months (range } 9-15 \text { ) }\end{array}$ & $\begin{array}{l}\text { We define participants lost to follow-up if they or their } \\
\text { treatment buddies were more than } 2 \text { months late for } \\
\text { a scheduled consultation or medication pick-up and } \\
\text { no information was found about the participant }\end{array}$ \\
\hline $\begin{array}{l}\text { Transfer out } \\
\text { (TO) }\end{array}$ & $\begin{array}{l}\text { Proportion of all participants who transferred out } \\
\text { to any other health facility (than the initially } \\
\text { attached one) with known outcome }\end{array}$ & $\begin{array}{l}6 \text { months (range } 5-8 \text { ) and } \\
12 \text { months (range 9-15) }\end{array}$ & $\begin{array}{l}\text { Definition of "known outcome": Documented proof of } \\
\text { follow-up visit or laboratory test of the new health } \\
\text { facility }\end{array}$ \\
\hline $\begin{array}{l}\text { Viral } \\
\text { suppression } \\
<1000 \\
\text { copies/ml }\end{array}$ & $\begin{array}{l}\text { Proportion of all participants with viral suppression } \\
(<1000 \text { copies } / \mathrm{mL})\end{array}$ & 12 months (range: 9-15) & $\begin{array}{l}\text { Some of the remote health facilities in the study } \\
\text { districts face regular challenges in sending the blood } \\
\text { to the government hospital. To ensure sufficient VL } \\
\text { measurements among study participants, these health } \\
\text { facilities will be equipped with dried-blood-spot (DBS) } \\
\text { as a backup for VL measurement. According to the } \\
W H O \text { the recommended threshold for treatment fail- } \\
\text { ure using DBS is } 1000 \text { copies } / \mathrm{mL}\end{array}$ \\
\hline Adherence & $\begin{array}{l}\text { Assessed by } 3 \text { different setting- and age-validated } \\
\text { ART self-reported adherence questions: } \\
\text { 1. "When was the last time you missed any } \\
\text { medications?" [i) past week, ii) } 1-2 \text { weeks ago, iii) } \\
3-4 \text { weeks ago, iv) never]: Dichotomous outcome } \\
\text { missed doses vs. no missed doses in the past } \\
\text { month } \\
\text { 2. "ART missed at two or more consecutive days } \\
\text { within last month?": Dichotomous outcome } \\
\text { 3. "How would you rate your adherence over the } \\
\text { last month" [i) very poor, ii) poor, iii) fair, iv) good, } \\
\text { v) very good, vi) excellent]: Dichotomous outcome } \\
\text { adherent vs non-adherent (anything less than } \\
\text { 'excellent') }\end{array}$ & $\begin{array}{l}3 \text { months (range } 2.5-3.5 \text { ), } \\
6 \text { months (range } 5-8 \text { ) and } \\
12 \text { months (range } 9-15 \text { ) }\end{array}$ & \\
\hline Quality of life & Assessed by SF-12 (Likert-Scale) & $\begin{array}{l}6 \text { months (range } 5-8 \text { ) and } \\
12 \text { months (range 9-15) }\end{array}$ & \\
\hline $\begin{array}{l}\text { Satisfaction } \\
\text { of care }\end{array}$ & $\begin{array}{l}\text { Assessed by a self-reported patient service satisfac- } \\
\text { tion questionnaire partly based on a setting- } \\
\text { validated quality of care questionnaire (Likert-Scale) }\end{array}$ & $\begin{array}{l}6 \text { months (range } 5-8 \text { ) and } \\
12 \text { months (range } 9-15 \text { ) }\end{array}$ & Assessed by an external data collector, not the PE \\
\hline
\end{tabular}

Twilio, certified with the privacy shield framework. Access to all data collection tools and databases are strictly limited and regulated through personal user profiles. The PEBRA trial represents implementation research without any experimental medication and only wellestablished ART in Lesotho according to the National guidelines. Thus, we do not expect serious adverse effects (SAE) on patients' health from this intervention. However, for the purpose of this trial, we will capture the following SAEs: a) life-threatening event, b) hospitalization, c) persistent or significant disability or incapacity, d) congenital anomaly / birth defect, e) death. It is not planned to establish a data safety and monitoring board.

\section{Sample size and analysis}

Based on cohort and program data from the study districts we expect on average 15 AYPLHIV per health facility with an overall viral suppression rate $(<20$ copies $/ \mathrm{ml}$ ) of $70 \%$. An overall target sample size of 300 AYPLHIV in 20 clusters would provide $90 \%$ power to detect a $20 \%$ increase of viral suppression in the intervention compared to the control group, assuming a type 1 error of 0.05 . An intra-cluster correlation coefficient (ICC) of 0.05 (design effect of 1.7) was estimated based on similar studies $[28,29]$.

Analyses are performed following the CONSORT guidelines for cluster-randomized trials and an intention-to-treat principle including all participants as 


\begin{tabular}{|c|c|c|c|c|}
\hline \multirow[b]{2}{*}{ TIMEPOINT } & \multirow{2}{*}{$\begin{array}{c}\text { Enrolment } \\
0\end{array}$} & \multicolumn{2}{|c|}{ Post-allocation } & \multirow{2}{*}{$\begin{array}{l}\text { Close-out } \\
12 \text { months } \\
\text { (range: } 9-15 \text { months) }\end{array}$} \\
\hline & & $\begin{array}{l}3 \text { months } \\
\text { (range: } 2.5-3.5 \text { months) }\end{array}$ & $\begin{array}{l}6 \text { months } \\
\text { (range: } 5-8 \text { months) }\end{array}$ & \\
\hline \multicolumn{5}{|l|}{ ENROLMENT: } \\
\hline Eligibility screen & $\mathrm{x}$ & & & \\
\hline Allocation (preset by cluster) & $x$ & & & \\
\hline \multicolumn{5}{|l|}{ INTERVENTIONS: } \\
\hline PEBRA model (Intervention) & $\rightleftarrows$ & & & $\longrightarrow$ \\
\hline Standard of care (Control) & $\longmapsto$ & & & $\longrightarrow$ \\
\hline \multicolumn{5}{|l|}{ ASSESSMENTS: } \\
\hline Sociodemographic factors & $\mathrm{x}$ & & & \\
\hline Socioeconomic data & $\mathrm{x}$ & & & \\
\hline Medical history & $\mathrm{x}$ & & & \\
\hline Adherence & $x$ & $x$ & $x$ & $x$ \\
\hline Quality of life & $x$ & & $x$ & $x$ \\
\hline Quality of care (satisfaction of care) & $\mathrm{x}$ & & $x$ & $x$ \\
\hline HIV knowledge & $\mathrm{x}$ & & & \\
\hline viral load & $(X)$ & & & $x$ \\
\hline
\end{tabular}

randomized per cluster randomization. Clusters are the unit of randomization, but individuals are the unit of analysis. The primary analysis uses random effects logistic regression models including cluster as a random effect and arm allocation as a fixed effect to assess the difference between viral suppression rate in the intervention versus control arm. The model will be further adjusted for the stratification factor, and relevant baseline factors that may be randomly unbalanced between intervention and control clusters. All results are presented with odds ratios and their respective $95 \%$ confidence intervals. Categorical variables will be described with absolute and relative frequencies and continuous variables as medians and interquartile ranges. In pre-specified subgroup analyses, the effect of gender, age groups, education, marital status, ART regimen and HIV/AIDS knowledge on key study outcomes will be assessed by including interaction terms in the model. If an interaction term is found to be significant, effect estimates will be summarized by subgroup. As the study is not powered for these pre-planned subgroup analyses, these results will be considered exploratory. Where substantial data are missing in important covariates, multiple imputation will be utilized and the results compared to models ignoring missing data. A sensitivity analysis will be performed to assess the effect of baseline viral load on the primary endpoint, only including participants for whom this data is available. All analyses are done using Stata (version 14, Stata Corporation, Austin, Texas, USA), using two-sided $p$-values and a significance level of 0.05 .

\section{Discussion}

Effective and differentiated strategies are needed to improve the HIV care cascade among adolescents and young adults, especially in rural settings in SSA. Although many countries in SSA have some sort of PE program in place, there is lack of published high-quality evidence for adolescent-specific DSD models involving peers [20].

The Zvandiri DSD model in rural Zimbabwe introduced community adolescent treatment supporters to offer facility-based as well as community-based support for AYPLHIV, including piloting ART delivery through peers. In a small randomized clinical trial the model improved self-reported adherence to ART, engagement in care, and psychosocial well-being [24]. This effect could no longer be observed at 2 years follow-up in a subsequent larger cluster-randomized trial, however, a $40 \%$ reduction in virologic failure was documented among participants in the model [25]. The questions remain, though, to what extent DSD models can be individualized and peers can be involved in clinical care. In recent years there has been an increasing programmatic shift towards DSD models, however they usually have narrow inclusion criteria and limited options to choose from. The PEBRA model tries to incorporate the existing structures and support options provided by different stakeholders, differentiates the DSD by personal preferences and puts the PE at the heart of the model.

This trial has several limitations. First, as in most operational research studies, we will have only limited control over what happens in our standard care clusters. Second, due to the nature of this pragmatic implementation trial, it is not possible to blind participants or staff to the intervention. Third, it was not feasible to perform the randomization after recruitment of the participants. That means, there is a possibility of recruitment bias. To mitigate this risk, two different consent forms for 
control versus intervention arm concealing the exact intervention of the other arm were used, thus the participants were aware of being in a study, but not of being in a trial.

The PEBRA trial will provide evidence on the feasibility and effectiveness of an inclusive and holistic DSD model for AYPLHIV that is more preference-based and coordinated by a PE. If proven to be effective, the PEBRA model and PEBRApp have the potential to be scaled up in similar settings.

\section{Trial status}

The trial was launched on November 4, 2019. The study is ongoing, and we expect to reach the required minimum target sample size within 5 months. The questionnaires, PEBRApp and the PEBRA model were pretested in a pilot trial from August - October 2019. The pilot trial assessed the acceptance of the PEBRA model and its delivery by the PE, the technical functionalities of PEBRApp and the questionnaires.

\begin{abstract}
Abbreviations
ART: Antiretroviral Therapy; AYPLHIV: Adolescents \& Young People Living with HIV; CAC: Community Adherence Clubs; Cl: Confidence Interval; CYC: Community Youth Club; DHMT: District Health Management Team; DSD: Differentiated Service Selivery; HIV: Human Immunodeficiency Virus; ICC: Intra-cluster correlation coefficient; LTFU: Loss-To-Follow-Up; OR: Odds Ratio; PE: Peer-Educator; PEBRA: Peer-Educator-Based Refill of ART; SAE: Serious Adverse Event; SSA: Sub-Saharan Africa; VHW: Village Health Worker; VL: Viral Load (Plasma HIV-1 RNA); WHO: World Health Organization
\end{abstract}

\section{Acknowledgements}

We would like to recognize the hard work and valuable contributions of the study staff in all three districts, the tireless support of the SolidarMed and Sentebale team in Lesotho as well as the District Health Management Teams. A special thanks goes to Tlotliso Mafantiri (Technify/T4A Lesotho) and Christoph Schwizer (www.christophschwizer.ch), who jointly developed the PEBRApp, as well as Ruben Dill for graphic designs. We thank the peereducators and the involved health facilities for their dedication to this project and we gratefully acknowledge the adolescents and young people living with HIV participating in this trial.

\section{Authors' contributions}

$A A$ is the principal investigator of this trial. AA, JAB, NDL, NB, MK, TIL, and TRG conceptualized and designed the trial. MK is the study coordinator. TIL is the local principal investigator. LC, JM, TM and TN provided technical support and critically revised the article for important intellectual content. All authors read and approved the final manuscript.

\section{Funding}

This trial is predominantly funded by the CIPHER grant from the International AIDS Society, obtained by AA. The Swiss Institute of Tropical and Public Health is the sponsor of the study. AA receives a salary through a grant from the MD-PhD program of the Swiss National Science Foundation (Grant 323530_177576). The study is embedded in the SolidarMed and Sentebale country programs and thus benefits from their logistics, administration and human resources. The funding sources have no role in the design of the study, and will not be involved in data collection, data analysis, interpretation of the results, or writing of the manuscript.

\section{Availability of data and materials}

The datasets used and analysed during the trial are available from the corresponding author on reasonable request.

\section{Ethics approval and consent to participate}

The trial protocol has been approved by the Ethical Board in Switzerland (Ethikkommission Nordwestschweiz; Req-2019-00480; June 14, 2019) and the Ministry of Health Research and Ethics Committee of Lesotho (118-2019; June 03, 2019). The trained PEs obtain the individual written informed consent from the participant before inclusion into the PEBRA study. In order to minimize selection bias, the ethics committees agreed to waive parental consent for the 15-17 years old study participants. Illiterate study participants provide a thumb-print and a literate witness (independent to the trial and chosen by the participant) co-signs the form. The informed consent is provided in the local language, Sesotho, and the participant receives a copy of the consent form. The participant has the right to withdraw consent at any time without giving reasons. In case of withdrawal, only data collected until the time of withdrawal will be used for research purposes (fully anonymized, identifier removed) and the participant will be managed according to standard of care. The results of this research project will be shared at three levels: (a) district level, during meetings headed by the district health management team, (b) national level, at the national research symposium of the Ministry of Health, and (c) international level through presentations at conferences and publication in peer-reviewed journals. The current version of the recommendations of the International Committee of Medical Journal Editors is followed regarding the eligibility of authorship and we do not intend to use a professional writer.

\section{Consent for publication}

Not applicable.

\section{Competing interests}

The authors declare that they have no competing interests.

\section{Author details}

${ }^{1}$ SolidarMed, Partnerships for Health, Lesotho. ${ }^{2}$ Department of Medicine, Clinical Research Unit, Swiss Tropical and Public Health Institute, Socinstrasse 57, 4051 Basel, Switzerland. ${ }^{3}$ University of Basel, Basel, Switzerland. ${ }^{4}$ Molecular Virology, Department of Biomedicine, University of Basel, Basel, Switzerland. ${ }^{5}$ Sentebale, Lesotho. ${ }^{6}$ District Health Management Team, Butha Buthe, Lesotho. ${ }^{7}$ Motebang Government Hospital, Leribe, Lesotho. ${ }^{8}$ Department of Infectious Diseases and Hospital Epidemiology, University Hospital Basel, Basel, Switzerland.

Received: 9 March 2020 Accepted: 16 March 2020

Published online: 30 March 2020

\section{References}

1. UNAIDS data 2019 [Internet]. Available from: https://www.unaids.org/en/ resources/documents/2019/2019-UNAIDS-data [cited 201925 Nov].

2. UNICEF HIV and AIDS data 2017 [Internet]. Available from: https://www. unicef.org/publicpartnerships/files/Annual_Results_Report_2017_HIV_And_ AIDS.pdf. [cited $202020 \mathrm{Mar}$.

3. Davies M-A, Pinto J. Targeting 90-90-90 - don't leave children and adolescents behind. J Int AIDS Soc. 2015;18(Suppl 6):20745 Available from: https://www.ncbi.nlm.nih.gov/pmc/articles/PMC4670834/ [cited $201925 \mathrm{Feb}]$

4. Slogrove AL, Mahy M, Armstrong A, Davies M-A. Living and dying to be counted: What we know about the epidemiology of the global adolescent HIV epidemic. J Int AIDS Soc. 2017;20 Available from: https://onlinelibrary. wiley.com/doi/abs/10.7448/IAS.20.4.21520 [cited 201925 Feb].

5. Bekker L-G, Siberry GK, Hirnschall G. Ensuring Children and Adolescents Are Not Left Behind. JAIDS J Acquir Immune Defic Syndr. 2018;78:S1 Available from: https://journals.lww.com/jaids/Fulltext/2018/08151/Ensuring_Children_ and_Adolescents_Are_Not_Left.1.aspx [cited 201925 Feb].

6. UNAIDS and UNICEF data 2018 [Internet]. Available from: https://www. childrenandaids.org/sites/default/files/2018-07/ALL-IN-in-Eastern-andSouthern-Africa-WEB_2018.pdf. [cited 202020 Mar].

7. Auld AF, Agolory SG, Shiraishi RW, Wabwire-Mangen F, Kwesigabo G, Mulenga $\mathrm{M}$, et al. Antiretroviral therapy enrollment characteristics and outcomes among HIV-infected adolescents and young adults compared with older adults--seven African countries, 2004-2013. MMWR Morb Mortal Wkly Rep. 2014;63(47):1097-103.

8. Plummer ML, Baltag V, Strong K, Dick B, Ross DA, World Health Organization, et al. Global Accelerated Action for the Health of Adolescents 
(AA-HA!): guidance to support country implementation [Internet]. 2017 [cited 2019 Feb 25]. Available from: http://apps.who.int/iris/bitstream/10665/ 255415/1/9789241512343-eng.pdf.

9. Hudelson C, Cluver L. Factors associated with adherence to antiretrovira therapy among adolescents living with HIV/AIDS in low- and middleincome countries: a systematic review. AIDS Care. 2015;27(7):805-16.

10. Govindasamy D, Ford N, Kranzer K. Risk factors, barriers and facilitators for linkage to antiretroviral therapy care: a systematic review. AIDS. 2012;26(16): 2059-67 Available from: http://journals.lww.com/aidsonline/Fulltext/2012/ 10230/Risk_factors,_barriers_and_facilitators_for.8.aspx.

11. Hall BJ, Sou K-L, Beanland R, Lacky M, Tso LS, Ma Q, et al. Barriers and facilitators to interventions improving retention in HIV care: a qualitative evidence meta-synthesis. AIDS Behav. 2017;21(6):1755-67.

12. McNairy ML, El-Sadr WM. The HIV care continuum: no partial credit given. AIDS Lond Engl. 2012;26(14):1735-8.

13. Joint United Nations Programme on HIV/AIDS. Miles to go: Closing gaps, breaking barriers, righting injustices. Geneva, Switzerland; UNAIDS; 2018 Available from: http://www.unaids.org/sites/default/files/media_asset/milesto-go_en.pdf [cited 201925 Feb].

14. Kanters S, Park JJH, Chan K, Socias ME, Ford N, Forrest Jl, et al. Interventions to improve adherence to antiretroviral therapy: a systematic review and network meta-analysis. Lancet HIV. 4(1):e31-40 Available from: http://dx.doi. org/10.1016/S2352-3018(16)30206-5 [cited 201713 Sep].

15. International AIDS Society. Differentiated Care for HIV: A Decision Framework for Antiretroviral Therapy. Durban, South Africa: IAS; 2016. Available from: http://www.differentiatedcare.org/Portals/0/adam/Content/yS6MGKB5EWs_uTBHk1C1Q/File/Decision\%20Framework.pdf [cited 201925 Feb].

16. WHO/IAS data 2018. Providing differentiated delivery to children and adolescents [Internet]. Available from: https://www.who.int/hiv/pub/ paediatric/diff-delivery-children-hiv/en/. [cited 202020 Mar].

17. Grimsrud A, Bygrave H, Doherty M, Ehrenkranz P, Ellman T, Ferris $R$, et al Reimagining HIV service delivery: the role of differentiated care from prevention to suppression. J Int AIDS Soc. 2016;19(1):21484 Available from: https://www.ncbi.nlm.nih.gov/pmc/articles/PMC5136137/.

18. PATA Technical Brief about Differentiated Service Delivery for Adolescents and Young Adults Living with HIV in South Africa 2019 [Internet]. Available from: http://teampata.org/wp-content/uploads/2019/02/DSD_Policy-Brief_2 019.pdf. [cited 202020 Mar].

19. A Decision Framework for differentiated antiretroviral therapy delivery for children, adolescents and pregnant and breastfeeding women. International AIDS Society 2017 [Internet]. Available from: http://www.differentiatedcare. org/Portals/0/adam/Content/9ErlJtsSfUmj_Ska6BoN0Q/File/Decision\%2 OFramework\%20for\%20children\%20adolescents\%20and\%20pregnant\%2 Oand\%20breastfeeding\%20women.pdf. [cited 202020 Mar].

20. WHO data 2019. Adolescent-friendly health services for adolescents living with HIV: from theory to practice [Internet]. Available from: https://www. who.int/publications-detail/adolescentfriendly-health-services-foradolescents-living-with-hiv. [cited 202020 Mar].

21. MacKenzie RK, van Lettow M, Gondwe C, et al. Greater retention in care among adolescents on antiretroviral treatment accessing 'Teen Club' an adolescent-centred differentiated care model compared with standard of care: a nested case-control study at a tertiary referral hospital in Malawi. J Int AIDS Soc. 2017. p. 20. https://doi.org/10.1002/jia2.25028.

22. Funck-Brentano I, Dalban C, Veber F, Quartier P, Hefez S, Costagliola D, et al. Evaluation of a peer support group therapy for HIV-infected adolescents. AIDS Lond Engl. 2005;19(14):1501-8.

23. Tsondai PR, Wilkinson LS, Grimsrud A, Mdlalo PT, Ullauri A, Boulle A. High rates of retention and viral suppression in the scale-up of antiretroviral therapy adherence clubs in Cape Town, South Africa. J Int AIDS Soc. 2017; 20:21649.

24. Willis N, Milanzi A, Mawodzeke M, Dziwa C, Armstrong A, Yekeye l, et al. Effectiveness of community adolescent treatment supporters (CATS) interventions in improving linkage and retention in care, adherence to ART and psychosocial well-being: a randomised trial among adolescents living with HIV in rural Zimbabwe. BMC Public Health. 2019;19(1):117.

25. Zvandiri Trial Policy Brief 2019 [Internet]. Available from: http://www. differentiatedcare.org/Portals/0/adam/Content/4QG5cuSbCkmSdl9p11 ywUQ/File/Zvandiri\%20Trial\%20Policy\%20Brief\%207\%20August\%202019.pdf. [cited $202020 \mathrm{Mar}$.
26. UNAIDS. Prevention Gap Report. 2016 [Internet]. Available from: http://www. unaids.org/sites/default/files/media_asset/UNAIDS_Gap_report_en.pdf. [cited 201610 Apr].

27. LePHIA report 2016-2017 [Internet]. Available from: https://phia.icap. columbia.edu/wp-content/uploads/2018/02/Lesotho-Summary-Sheet_A4.2. 7.18.HR_pdf. [cited 202020 Mar].

28. Elul B, Lamb MR, Lahuerta M, Abacassamo F, Ahoua L, Kujawski SA, et al. A combination intervention strategy to improve linkage to and retention in HIV care following diagnosis in Mozambique: A cluster-randomized study. PLOS Med. 2017;14(11):e1002433 Available from: http://journals.plos.org/ plosmedicine/article?id=10.1371/journal.pmed.1002433 [cited 20189 Jan].

29. McNairy ML, Lamb MR, Gachuhi AB, Nuwagaba-Biribonwoha H, Burke S, Mazibuko $\mathrm{S}$, et al. Effectiveness of a combination strategy for linkage and retention in adult HIV care in Swaziland: The Link4Health cluster randomized trial. PLOS Med. 2017;14(11):e1002420 Available from: http:// journals.plos.org/plosmedicine/article?id=10.1371/journal.pmed. 1002420 [cited $20189 \mathrm{Jan}$.

\section{Publisher's Note}

Springer Nature remains neutral with regard to jurisdictional claims in published maps and institutional affiliations.
Ready to submit your research? Choose BMC and benefit from:

- fast, convenient online submission

- thorough peer review by experienced researchers in your field

- rapid publication on acceptance

- support for research data, including large and complex data types

- gold Open Access which fosters wider collaboration and increased citations

- maximum visibility for your research: over $100 \mathrm{M}$ website views per year

At $\mathrm{BMC}$, research is always in progress.

Learn more biomedcentral.com/submissions 